\title{
SAÚDE MENTAL E TRABALHO: DO SOFRIMENTO AO ADOECIMENTO PSÍQUICO NAS ORGANIZAÇÕES FRENTE ÀS TECNOLOGIAS E FORMAS DE GESTÃO
}

\section{ARTIGO DE REVISÃO}

PEREIRA, Letícia Rossetti ${ }^{1}$

SCATOLIN, Henrique Guilherme ${ }^{2}$

PEREIRA, Letícia Rossetti. SCATOLIN, Henrique Guilherme. Saúde Mental e Trabalho: Do sofrimento ao adoecimento psíquico nas organizações frente às tecnologias e formas de gestão. Revista Científica Multidisciplinar Núcleo do Conhecimento. Ano 05, Ed. 03, Vol. 09, pp. 139-152. Março de 2020. ISSN: 24480959, Link de acesso: https://www.nucleodoconhecimento.com.br/psicologia/saudemental-e-trabalho

\section{RESUMO}

O presente artigo tem como objeto de estudo realizar uma apresentação e discussão acerca do sofrimento e adoecimento psíquico nas organizações da atualidade, questionando sobre a seguinte problemática: como que uma organização pode anular o indivíduo e quais são os fatores que levam ao adoecimento e sofrimento no trabalho? Conclui-se que estudos acerca dessa temática se faz importante para melhorar questões de saúde mental no trabalho e ter um novo olhar através dos referenciais da psicodinâmica dejouriana, baseando na subjetividade do indivíduo.

Palavras Chaves: Adoecimento psicodinâmica, saúde mental.

${ }^{1}$ Possui graduação em Psicologia pelo Centro Universitário Herminio Ometto de Araras(2009), pós-graduada em Psicologia organizacional e do Trabalho.

2 Doutor em Psicologia Clínica pela PUC-SP, mestre em Psicologia Clínica, graduação em Psicologia pela Unimep (Universidade Metodista de Piracicaba). 


\section{INTRODUÇÃO}

O trabalho é essencial para construção da identidade e desenvolvimento pessoal do indivíduo, mas quando o ambiente de trabalho é desfavorável, este pode contribuir para o adoecimento do trabalhador. $\mathrm{O}$ trabalho pode ser compreendido como um reduto de prazer e do crescimento, acenando para a possibilidade de se ter uma ocupação laboral e uma ascensão social, com trocas e experiências psicossociais, mas também pode se tornar uma fonte geradora de sofrimento e de adoecimento (SIMOES, 2013).

Dessa perspectiva, o trabalho pode ser considerado fonte de vida capaz de conferir identidade ao ser humano tanto no plano pessoal como no social, mas abre também a possibilidade de compreender o trabalho como uma poderosa fonte de adoecimento psicossomático e social, uma vez que o desgaste, o estresse e as condições ambientais do trabalho podem romper o equilíbrio psicossomático do trabalhador.

Portanto, essa pesquisa tem como objeto de trabalho a apresentação e discussão sobre o sofrimento e o adoecimento psíquico nas organizações. Este é um tema que vem sendo bastante discutido na atualidade. Sobre isto, Vieira, Guimaraes e Martins (1999) destacam que nos últimos anos, o papel do psicólogo em relação à saúde mental dos colaboradores ocupou espaços em estudos e pesquisas, examinando os aspectos positivos e negativos que o mesmo possa vir a assumir frente à saúde do trabalhador.

Devido as novas tecnologias, impactos ambientais e as novas formas de gestão, ocorreu um aumento significativo de pessoas adoecidas nas organizações. Como aponta Silva, Bernardo e Souza (2016), o mundo do trabalho, na atualidade, apresenta diversos problemas no aspecto físico e mental para os trabalhadores, provocados pelas tecnologias, globalização e pelos impactos ambientais.

Assim, as transformações nos processos de trabalho foram ocorrendo com a evolução tecnológica, demonstrando um aumento da competitividade, pois os trabalhadores começaram a ter medo de serem superados pelas máquinas e também 
pela necessidade de se adaptarem a elas, o que acarretou um aumento de ansiedade, tensão e insegurança, gerando sofrimento psíquico ao trabalhador (SIMÕES, 2013).

Em relação à isso, Camargo e Oliveira (2004) destacam que, desde a antiguidade há relatos sobre os impactos do ambiente e da tecnologia na saúde do trabalhador, mas somente na metade do século passado que foram asseguradas leis e estudos para tais prevenções.

A partir deste contexto, o presente estudo se propõe a discorrer sobre a seguinte problemática: como que a organização pode anular o indivíduo, fazendo com que aumente o sofrimento e trazendo grandes malefícios à saúde mental do trabalhador?

\section{METODOLOGIA}

O presente estudo refere-se a uma pesquisa bibliográfica de caráter qualitativo. Tem como objetivo principal aprofundar em conhecimentos e discussões sobre o sofrimento e adoecimento psíquico nas organizações. Nesta pesquisa foi utilizado teorias da Psicodinâmica do Trabalho com o objetivo de refletir acerca da atualidade nas organizações. Minayo (2001) aponta que a pesquisa qualitativa tem como objetivo responder questões particulares, trabalhando com os significados, crenças e valores.

Sobre a pesquisa bibliográfica, Minayo (2001, p.53) nos ensina que esta:

(...) coloca frente a frente os desejos do pesquisador e autores envolvidos em seu horizonte de interesse. Esse esforço em discutir ideias e pressupostos tem como lugar privilegiado de levantamento as bibliotecas, os centros especializados e arquivos.

Portanto, para a realização da pesquisa, o acesso à bibliografia foi feito manualmente e eletronicamente, pesquisando livros em bibliotecas e fazendo buscas pela internet. Para obtenção de dados bibliográficos foram utilizados livros presentes na biblioteca da FHO (Fundação Hermínio Ometo), as bases de dados Scientific Electronic e da Library Online (SciELO). 
$\mathrm{Na}$ busca dos artigos foram utilizadas as seguintes palavras chaves: adoecimento no trabalho, saúde mental e psicodinâmica do trabalho. $O$ trabalho foi realizado a partir da perspectiva da Escola Dejouriana, por meio da leitura, análise e interpretação dos escritos de Christophe Dejours, bem como de outros autores importantes nesta área.

\section{FUNDAMENTAÇÃO TEÓRICA}

A concepção de trabalho possui diversos significados, mas sempre com o intuito da sobrevivência e da realização. De acordo com Krawulski (1998, s/p)

trabalho é um termo masculino que, em sua forma substantiva, quer dizer exercício, aplicação de energia física em algum serviço, numa profissão, ocupação, mister, ofício, labuta, esforço; esmero, cuidado, dedicação, feitura de uma obra; a própria obra já executada; livro, compêndio; escultura, pintura; aflição, sofrimento; parto (apud BUENO, 1988).

Segundo o mesmo autor, o trabalho é compreendido como meio de realizar a satisfação das necessidades, bem como permitir a busca da autorrealização (Krawulski,1998). O processo de trabalho é um produto para satisfazer as necessidades humanas, que ao longo da história, tem passado por inúmeras transformações.

Sato (2002) nos ensina que há cerca de duas décadas, novas palavras e expressões tem dado um novo significado ao cenário atual do trabalho como empreendedorismo, comprometimento, requalificação, globalização, entre outras. Para sobreviver nessa realidade, precisamo-nos "conectar"; ou seja; estar ligado as novas tecnologias que vão surgindo a todo momento. Porém, segundo o mesmo autor, embora mudanças estejam ocorrendo, há uma contradição totalmente exposta nas indústrias, uma vez que nestas "convivem linhas de montagem fordistas com máquinas de última geração automatizadas" (2002, p.33). Trabalhos repetitivos continuam sendo executados e realçando as estatísticas de doenças e acidentes de trabalho. Em relação a isso, Ribeiro (1999) aponta que, nos dias atuais, se utiliza menos horas de trabalho para 
produzir a mesma quantidade de produtos, fazendo assim com que trabalhadores apresentam um crescimento explosivo das LER e diversos outros adoecimentos.

Portanto, a partir dessas mudanças no mundo do trabalho e do aumento de doenças e do sofrimento no trabalho, este artigo tem por objetivo apresentar discussões para contribuir com a compreensão desse fenômeno.

Tal problemática será discutida no decorrer deste artigo com apoio das teorias de psicodinâmica do trabalho (de Dejours) a fim de pensar sobre a anulação do indivíduo, tornando-o vítima de seu trabalho. A análise será feita a partir dos resultados deste trabalho, pautando-se nos pressupostos de Dejours (1994), Freud (1921; 1930), Antunes e Praun (2015); entre outros autores que nos ajudam a discorrer sobre esta temática.

\section{RESULTADOS E DISCUSSÃO}

Na década de 1990, com as reestruturações no modo do trabalho, muitas mudanças começaram a ocorrer, fazendo com que os trabalhadores buscassem novos conhecimentos. Em relação a isso, Goulart e Guimarães (2002) apontam que foi uma mudança do componente manual de trabalho para o intelectual. As novas tecnologias passaram a exigir do trabalhador interpretação de textos, comunicação, trabalho em equipe, entre outros. As formas de gestão começam a ser substituídas por modelos baseados na excelência, ao desafio permanente, polivalência da mão de obra, formas de gestão que seguem o modelo japonês Toyotista, focando na alta produtividade e baixos custos de produção. Assim, com a qualificação do trabalhador obtêm-se o enxugamento da empresa, fazendo com que o trabalhador desempenhe diversas funções (CHANLAT, 2006 citado por GOULART e GUIMARAES, 2002).

Em relação à essa nova reestruturação, Clot (2006) afirma que é necessário aos trabalhadores uma disponibilidade cada vez maior para agir em meios profissionais cada vez mais incertos e que exigem que eles deem sempre mais de si mesmos. Porém, com a produção em massa, a ampliação, o controle e intensificação 
do trabalho, novas formas de acidentes e adoecimentos com nexo laboral passaram a fazer parte das empresas; como aponta Antunes e Praun:

(...) os trabalhadores pertencentes ao núcleo que atua com maquinário mais avançado, dotado de maior tecnologia, encontram-se cada vez mais expostos à flexibilização e à intensificação do ritmo de suas atividades, expressas não somente pela cadência imposta pela robotização do processo produtivo, mas, sobretudo, pela instituição de práticas pautadas pela multifuncionalidade, polivalência, times de trabalho interdependentes, além da submissão a uma série de mecanismos de gestão pautados na pressão psicológica voltada para o aumento da produtividade (2015, p. 411).

Segundo os mesmos autores, a flexibilização é vista como base do adoecimento nos dias atuais. Ela faz com que o trabalhador tenha a sensação de que o dia foi comprimido. Trabalhadores passam a se desdobrar para executarem sozinhos o que antes era realizado por dois ou mais trabalhadores. "Assim como a obsessão dos gestores do capital em eliminar completamente os tempos mortos do processo de trabalho, tem convertido paulatinamente, o ambiente de trabalho em espaço de adoecimento". (ANTUNES e PRAUN, 2015 p. 414).

Em relação ao sofrimento e adoecimento no ambiente de trabalho, Dejours (1994) destaca que estes ocorrem quando a relação do trabalhador com a organização é bloqueada e "a energia pulsional, que não acha descarga no exercício do trabalho, se acumula no aparelho psíquico, ocasionando um sentimento de desprazer e tensão"(p.29). Ainda segundo este autor, todo excesso conduz ao aparecimento da fadiga do sofrimento, podendo desencadear assim a patologia. Entretanto, apesar do sofrimento ser inerente ao processo de trabalho, é impossível de ser eliminado e, muitas vezes, não se torna patogênico. O sofrimento pode pender para o lado da criatividade e beneficiar a identidade do indivíduo. Neste meandro, tudo vai depender da estruturação do indivíduo em sua história de vida, bem como a organização do trabalho e suas relações interpessoais na organização (CODO; SORATO; VASQUESMENEZES, 2004). 
A gestão por metas começou a ser disseminada nas organizações em meados da década de 1980. É vista também como um dos fatores para o adoecimento do indivíduo, visto que mantem o foco na crescente mensuração de resultados. É neste momento que começam a serem inseridas estratégias corporativas; como participação de lucros e resultados ou participação de resultados (ANTUNES e PRAUN, 2015). Nesse sentido, a PLR/PR é tida como

um mecanismo mais para alavancar o ritmo de produção, a disciplinarização do trabalho, bem como o ambiente difuso de vigilância entre os trabalhadores. Essa disciplina e vigilância, muitas vezes, prescinde da presença direta do chefe (ANTUNES e PRAUN, 2015, p. 418).

Esse modelo de gestão faz com que aumente a competitividade dos indivíduos na busca de produtividade, descartando o trabalho em equipe e retomando os paradigmas da antiga gestão, Como aponta Lorentz, Lima e Maestro Filho:

Na busca de produtividade e competitividade, certos modelos de gestão valorizam estilos mais agressivos ou, até mesmo, fomentam o aumento nos índices de conflito para estimular a concorrência interna e externa. Entretanto, este tipo de gestão nem sempre se mostra eficaz e pode ser prejudicial, tanto para a empresa quanto para os funcionários, pois descartam colaboração e fragmentam equipes" (LORENTZ; LIMA e MAESTRO FILHO, 2011, p. 8).

Anteriormente, quando não tinha a existência do modelo de gestão por competências, existia os laços de solidariedade entre os trabalhadores, laços estes que cooperavam para a saúde do trabalhador, pois havia cooperação, proteção e conforto em situações de sofrimento. E "(...) é essa quebra dos laços de solidariedade e, por conseguinte, da capacidade do acionamento das estratégias coletivas de defesa entre os trabalhadores que se encontra na base do aumento dos processos de adoecimento psíquico." (DEJOURS e BĖGUE, 2010 apud ANTUNES e PRAUN, 2015, p.414). 
De acordo com os mesmos autores citados acima, antes do modelo de gestão por competências, a coletividade fazia com que as situações de sofrimento pudessem ser amenizadas, pois havia um pacto de apoio subjetivo mútuo. Muitas vezes, quando o indivíduo não conseguia dissimular seu sofrimento, os próprios laços de solidariedade constituídos tinham a função de protegê-lo (ANTUNES e PRAUN, 2015).

$\mathrm{Na}$ atualidade, verifica-se o trabalho como um espaço mecanicista, focando cada vez mais nos resultados e lucros imediatos, não compreendendo o trabalho como um lugar de trocas de experiências, onde os indivíduos podem expressar suas criatividades e potenciais, como destaca Moreira, Maciel e Araújo:

Os objetivos da empresa são introjetados e o controle do externo passa a ser internalizado pelos sujeitos, em uma espécie de "usurpação" do desejo. Nessas condições, os trabalhadores passam a não mais encontrar razões para exercer suas funções, mostrando-se descrentes e pessimistas. $O$ trabalho, embora ainda central para a identidade, deixa de exercer uma função organizadora e estruturante nos indivíduos, passando a ocupar um lugar de desvalorização do humano, afetando os vínculos sociais que se estabelecem nos locais de trabalho e com familiares e amigos. (2013, p.46)

O trabalho se torna vazio de significados, fazendo com que os indivíduos se sintam desamparados e frustrados. O ambiente de trabalho influencia o modo de vida do indivíduo, especialmente porque é nele que o indivíduo passa a maior parte de seu tempo e onde estabelece seus vínculos sociais. Sendo assim, se os vínculos forem pobres e hostis, o ambiente de trabalho torna-se um local de patologias e psicopatologias, sendo a mais presente delas a depressão (MOREIRA; MARCEL e ARAÚJO, 2013).

Sobre a depressão no trabalho, Dejours destaca que:

A vivência depressiva condensa de alguma maneira os sentimentos de indignidade, de inutilidade pelo cansaço. Cansaço que se origina não só 
dos esforços musculares e psicossensoriais, mas que resulta sobretudo do estado dos trabalhadores taylorizados. Executar uma tarefa sem investimento material ou afetivo exige a produção de esforço e de vontade, em outras circunstâncias suportada pelo jogo da motivação e do desejo. A vivência depressiva alimenta-se da sensação de adormecimento intelectual, de anquilose mental, de paralisia da imaginação e marca o triunfo do condicionamento ao comportamento produtivo (1992, p. 42).

A falta de investimento na tarefa faz o indivíduo se sentir inútil, sem sentido, surgindo assim a depressão que se manifesta através do cansaço, fazendo com que o trabalhador perca sua capacidade de desenvolvimento criativo e intelectual. Portanto, é a relação da satisfação com a tarefa, juntamente com o perfil da organização, que vai determinar o sofrimento no trabalho. Como cita Dejours:

[...] quanto mais a organização do trabalho é rígida, mais a divisão do trabalho é acentuada, menor é o conteúdo significativo do trabalho e menores são as possibilidades de mudá-lo. Correlativamente, o sofrimento aumenta (1992, p. 52).

Em O Mal Estar na Civilização, Freud (1929) já destacava que o sofrimento nos ameaça a partir de três direções, sendo uma delas a que descreve o nosso relacionamento com outros indivíduos. O sofrimento é algo inerente ao ser humano e a vida em sociedade, estando, portanto, presente nas organizações. Freud (1929) relata que diante do sofrimento, muitas vezes, o indivíduo utiliza-se de estratégias defensivas que é o caso da sublimação (transformação de impulsos indesejados em algo menos prejudicial). Rodrigues, Álvaro, Rondina (2006, s/p) destacam que:

A origem do sofrimento, por sua vez, tem suas raízes na história singular de toda pessoa. $\mathrm{O}$ autor diz que o sofrimento repercute naquilo que ele chama de "teatro do trabalho", ao entrar numa relação com a organização do trabalho. Dejours quer dizer, com isso, que o sofrimento é individualizado e depende da construção social e psíquica de cada 
pessoa. E que isso, invariavelmente, acaba repercutindo no ambiente de trabalho, em seu "teatro", com os seus "personagens".

O sofrimento aparece quando a energia pulsional se acumula no aparelho psíquico, não achando descarga no exercício do trabalho, que vai depender da estrutura mental do indivíduo. Nas palavras de Deujours:

Para transformar um trabalho fatigante em um trabalho equilibrante precisa-se flexibilizar a organização do trabalho, de modo a deixar maior liberdade ao trabalhador para rearranjar seu modo operário e para encontrar os gestos que são capazes de lhe oferecer prazer, isto é, uma expansão ou uma diminuição de sua carga psíquica no trabalho(1994, p.32).

Freud (1929/1974, p.174) já destacava que a atividade profissional só poderia trazer satisfação se pudesse ser livremente escolhida, como podemos ver na citação abaixo:

A atividade profissional constitui fonte de satisfação, se for livremente escolhida, isto é, por meio de sublimação, tornar possível o isso de inclinações existentes, de impulsos instintivos (pulsionais) resistentes ou constitucionalmente. No entanto, como caminha para felicidade, o trabalho não é altamente prezado pelos homens. Não se esforçam em relação a eles como fazem em relação a outras possibilidades de satisfação. A grande maioria das pessoas só trabalha sob a pressão da necessidade, e essa natural aversão humana ao trabalho suscita problemas extremamente difíceis.

Os impactos das tecnologias e das novas formas de gestão, com exigências de qualificação profissional, competitividade e flexibilização, tem demonstrado diversos efeitos acerca da saúde mental do trabalhador. Muitas vezes, o indivíduo necessita adquirir novas competências para atender as perspectivas da organização, podendo causar, em sua subjetividade, sensações de incompetência e insegurança. Situações 
como essas pode se tornar um elemento perigoso ao indivíduo ou suscitar estratégias defensivas que podem ser tanto coletivas como individuais.

Ainda neste contexto, Oliveira e Mendes apontam:

Uma divisão ainda mais específica sobre as estratégias defensivas é feita por Dejours (2004), em que ele as classifica em defesas (a) de proteção, (b) de adaptação e (c) de exploração. As defesas de proteção são formas de pensar e agir de modo a proteger-se do sofrimento advindo do trabalho e fazem com que esse sofrimento seja racionalizado ou evitado. Com isso, essas defesas auxiliam o trabalhador a tornar-se alheio às causas do sofrimento, tendo por consequências a intensificação deste ou o adoecimento. Já as defesas de adaptação e de exploração estão relacionadas à submissão aos desejos de produção da organização, em que o trabalhador se sujeita a comportamentos inconscientes que atendam à produção e ao funcionamento, por vezes, perverso da organização do trabalho (2014, p. 392).

Portanto, verifica-se que através da teoria dejouriana, estratégias de como o trabalhador vai enfrentar o sofrimento vai definir se irá gerar um adoecimento psíquico (ou não). A escolha das vias de descarga da energia pulsional vai depender do funcionamento psíquico de cada indivíduo, ocorrendo "em função de características pessoais, desejos, aspirações, motivações e necessidades psicológicas que integram a vida do indivíduo, não sendo, portanto, igual para todos." (PEREIRA; VIEIRA, 2011, p. 3).

\section{CONCLUSÃO}

Essa pesquisa teve como objetivo discutir sobre as novas configurações que o trabalho vem se estruturando e as suas consequências para a saúde mental do trabalhador, iniciando com o seu sofrimento até o seu adoecimento. 
Há vários elementos que compõem o processo de transformação do sofrimento em adoecimento, como os ritmos de trabalho, multiplicação de tarefas, gestão por metas, entre outros. Considerando os conceitos trabalhados até o devido momento, pode-se notar que o trabalho é um componente que pode atuar como proteção à saúde, como gerador de prazer, reconhecimento, entre outros. Entretanto, suas condições podem gerar malefícios à saúde como sofrimentos e doenças. Neste meandro, o trabalho não pode ser visto apenas como algo negativo na vida do indivíduo; mas, na maioria das vezes, tem acarretado sofrimento e adoecimento. É de grande valia estudos acerca dessa temática para que possamos contribuir com a melhora na questão que envolva saúde mental e trabalho. Seria interessante ressaltar que a importância da Saúde Mental é reconhecida pela Organização Mundial da Saúde como um estado de completo bem-estar físico, mental e social (CAMARGO, NEVES, 2004).

Assim, no decorrer deste trabalho, a psicodinâmica dejouriana contribuiu com a problemática estudada através de um novo olhar e entendimento do sofrimento psíquico, baseando-se na subjetividade do indivíduo e na sua respectiva compreensão, uma vez que esta não se preocupa em detectar as doenças mentais do trabalho, mas sim um sentido para a relação entre o Homem e o Trabalho, além das estratégias defensivas utilizadas como procedimento regulatório do sofrimento vivenciado no trabalho (OLIVEIRA e MENDES, 2009).

\section{REFERÊNCIAS}

ANTUNES, Ricardo; PRAUN, Luci. A sociedade dos adoecimentos no trabalho. Serv. Soc. Soc., São Paulo, n. 123, p. 407-427, Sept. 2015. Available from $<$ http://www.scielo.br/scielo.php?script=sci_arttext\&pid=S0101$66282015000300407 \&$ Ing $=$ en\&nrm=iso $>$. access on 01 Sept. 2018. http://dx.doi.org/10.1590/0101-6628.030.

CLOT, Yves. A função psicológica do trabalho. Petrópolis: Vozes, 2006. 
CODO, W; SORATTO, L. \& Vasques-Menezes. Saúde mental e trabalho In: J. C. Zanelli, J. E. Borges-Andrade \& A. V. B. Bastos, (Org.), Psicologia, organizações e trabalho no Brasil. (pp 276-299). Porto Alegre: Artmed, 2004.

CAMARGO, Duílio Antero de; NEVES, Sergio Nolasco Hora das. Transtornos mentais, saúde e trabalho: Serie Saúde Mental e trabalho. São Paulo: Casa do Psicólogo, 2004, 23-42, p. v. 3.

DEJOURS, Jacques Christophe. Psicodinâmica do trabalho: contribuições da escola dejouriana à análise da relação prazer, sofrimento trabalho. São Paulo: Atlas, 1994.

A loucura do trabalho: estudo de psicopatologia do trabalho. São Paulo: Cortez-Oboré, 1992.

FREUD, S. (1929). O Mal Estar na Civilização. Rio de Janeiro: Imago, 1977.

GOULART, I.B, GUIMARAES, R.N. Cenários contemporâneos do mundo do trabalho: In: Goulart IB, organizador. Psicologia organizacional e do trabalho: teoria, pesquisa e temas correlatos. São Paulo: Casa do Psicólogo; 2002.

KRAWULSKI, Edite. orientação profissional e o significado do trabalho. Rev. ABOP, Porto Alegre, v. 2, n. 1, p. 5-19, 1998 .Disponível em $<$ http://pepsic.bvsalud.org/scielo.php?script=sci_arttext\&pid=S1414$88891998000100002 \&$ lng=pt\&nrm=iso $>$. acessos em 12 set. 2018

LORENTZ, Cacilda Nacur; LIMA, Luiz Cláudio de; MAESTRO FILHO, Antonio Del. Assédio Moral: Reflexões sobre seus Impactos nas Organizações, no Papel e naResponsabilidade dos Profissionais de Recursos Humanos. EnANPAD, Rio de Janeiro, 2011. Disponível em: <http://www.anpad.org.br/admin/pdf/GPR2443.pdf>. Acesso em: 15 de maio de 2018.

MINAYO, M. C. de S (org.). Pesquisa Social. Teoria, método e criatividade. 18 ed. Petrópolis: Vozes, 2001. 
MOREIRA, Virginia; MACIEL, Regina Heloisa; ARAUJO, Thalita Queiroz de. Depressão: os sentidos do trabalho. Rev. NUFEN, São Paulo , v. 5, n. 1, p. 4556, 2013

$<$ http://pepsic.bvsalud.org/scielo.php?script=sci_arttext\&pid=S2175-

$25912013000100006 \&$ Ing=pt\&nrm=iso>. acessos em 29 ago. 2018.

OLIVEIRA, Juliana Nunes de; MENDES, Ana Magnólia. Sofrimento psíquico e estratégias defensivas utilizadas por desempregados: contribuições da psicodinâmica do trabalho. Temas psicol., Ribeirão Preto , v. 22, n. 2, p. 389399, dez. 2014.

$<$ http://pepsic.bvsalud.org/scielo.php?script=sci_arttext\&pid=S1413-

389X2014000200011\&lng=pt\&nrm=iso>.

acessos

em 01 set. 2018. http://dx.doi.org/10.9788/TP2014.2-10

RIBEIRO, HP. A violência oculta do trabalho: as lesões por esforços repetitivos [online]. Rio de Janeiro: FIOCRUZ, 1999.

RODRIGUES, Patricia Ferreira; ALVARO, Alex Leandro Rexeira; RONDINA, Regina. Sofrimento no Trabalho na Visão de Dejours. Revista científica eletrônica de psicologia. 7.ed. nov/2006.

Disponível

em:

http://www.faef.revista.inf.br/imagens_arquivos/arquivos_destaque/lh21 pliEajxIWcK_ 2013-5-10-15-30-2.pdf>. Acesso em:06 jun.2018

SATO, L. Prevenção de agravos à saúde do trabalhador: replanejando o trabalho através das negociações cotidianas. Cadernos de Saúde Pública, 2002.

SIMÕES, F. I. W.; F. Adoecimento no trabalho: um estudo de caso. R. Laborativa. v. 2, n. 2, p. 73-85, out./2013. http://ojs.unesp.br/index. php/rlaborativa.

SILVA, Mariana Pereira da; BERNARDO, Marcia Hespanhol and SOUZA, Heloísa Aparecida. Relação entre saúde mental e trabalho: a concepção de sindicalistas e possíveis formas de enfrentamento. Rev. bras. saúde ocup. [online]. 2016, vol.41, e23. Epub Dec 12, 2016. ISSN 0303-7657. http://dx.doi.org/10.1590/23176369000003416. 
VIEIRA, Lueclia Chiavegato; GUIMARAES, Liliana A. M.; MATINS, Daniela de A. : Serie Saúde Mental e trabalho. Sao Paulo: Casa do Psicologo, 1999. 169-185 p. v. 1.

Enviado: Setembro, 2019.

Aprovado: Março, 2020. 